Studies in African Linguistics

Volume 28, Number 1, Spring 1999

\title{
THE NOUN CLASSES AND CONCORD OF CONGO COPPERBELT SWAHILI*
}

\author{
Nkulu Kabuya \\ Institut Pédagogique National, Kinshasa
}

\begin{abstract}
This paper reconsiders claims that the Swahili of the Congo Copperbelt area has a limited noun class system and an inconsistent system of agreement. It shows that there are, operating side-by-side with the simple system generally presented by scholars, a noun class and concord system of the original Bantu type, and that the prefixes of the latter are in free variation with those of their simplified versions. This free variation is discussed from grammatical, sociolinguistic, and stylistic perspectives. The conclusion reached is that by spreading change in its lexicon and morphosyntax, Congo Copperbelt Swahili has developed a system of singular/plural prefixes that will eventually replace the traditional class system.
\end{abstract}

\section{Introduction}

The noun class and concord system of what is generally called Lubumbashi Swahili, but is here designated Congo Copperbelt Swahili (hereafter CCS), has received a lot of attention from scholars. The prevailing argument in the literature is that this language has a limited number of noun class prefixes and an inconsistent system of agreement [Polomé 1968, 1971, 1982, 1983; Bokamba 1977; Gilman 1985; Rossé 1977]. This characterisation of the CCS noun class and concord system is generally taken for granted and quoted particularly by scholars who, like Ohly [1988], are interested in other areas of CCS than syntax.

I show two basic things in what follows: (1) that CCS has a range of prefix shapes and a concord system that corresponds in general outline to that found in East African Swahili and other Bantu languages; and (2) that part of this system of noun classification and related concord operates side-by-side with the sim-

\footnotetext{
* I am grateful to the editor and to an anonymous SAL reviewer for their invaluable comments on the drafts to this paper. I nevertheless take full responsibility for the paper contents at present.
} 
plified system which other scholars have identified and emphasised to the point of overlooking the former. I further try to explain the noted variatlon in terms of syntactic environment, and sociolinguistic and stylistic variables. Before doing all this, I first discuss the source of the data supporting the analysis.

\section{Source of data}

The present analysis is based primarily on empirical data obtained from various sources. These include:

- recordings of spontaneously delivered conversations and accounts of elicited talk such as narratives;

- a recording of talk at a dowry ceremony;

- a perusal of letters, 20 genuine and 10 elicited; and

- consultation sessions during which informants were asked to decide whether or not they felt that the 20 genuine letters submitted to them were written by competent CCS speakers. Informants were invited to rewrite letters with dubious expressions in what they regarded as 'acceptable' CCS.

To take part in these activities, one needed to have been born in Lubumbashi or in another urban centre of the CCS domain and not to have lived in a speech community with another variety of Swahili.

The data thus collected were backed up by tests of grammaticality and acceptability judgements conducted with fellow native speakers of CCS. These were carried out in the form of interviews on the topics of noun class and concord. The informants were presented with items which, based on my own intuition as a native speaker of CCS, I considered inadequately described in previous work. It was the informant's duty to decide whether in his or her view the structure of those items was acceptable and grammatical by CCS standards or not. Provision was also made for the informant to offer alternative constructions in cases of dissatisfaction.

In an effort to rely on empirical data as much as possible, I have refrained from using made-up sentences (or parts thereof) to illustrate matters in the analysis. Preference is given to constructions that actually occurred in the data.

\section{CCS Noun Prefixes, Classes, and Concord}

3.1. The common Bantu pattern. The data show that, like all other Bantu languages, CCS has a large number of noun prefixes commanding alliterative concord. Evidence of this is provided in (1) where the noun prefixes and the other members of concord sets are underlined. ${ }^{1}$

(1)
a. $\underline{B}$ a toto
$\underline{b a}-$ mingi $\underline{b}-a$
iki
ki-pande ba-li-kwa-ka-po
2-children 2-many 2-CON DEM.7 7-piece 2-PST-be-ASP-LOC
'Many children from this area were there.'

1 Abbreviations: $\mathrm{ASP}=$ aspect, $\mathrm{CON}=$ Connective, $\mathrm{DEM}=$ demonstrative, $\mathrm{LOC}=$ Locative, $\mathrm{NEG}=$ negative, $\mathrm{PST}=$ past, $\mathrm{PR}=$ present. Numbers in examples correspond to noun classes. 
b. Idi di-cafu di-ote di-li-kwa di-a ku-vimba.

DEM.5 5-cheek 5-all 5-PST-be 5-CON 15-swell

'This whole cheek was swollen.'

c. I $\underline{k i} \quad \underline{k}$-bambashi $\underline{k y}$-ote, ba-lisha ku- $\underline{k}$ i-pomona.

DEM.7 7-wall 7-all 2-ASP 15-7-destroy

'This entire wall has been destroyed.'

d. $\underline{B} \underline{i}-1 e \quad \underline{b i-n t u} \quad \underline{b i}-o t e \underline{b i}-l i-k w a-k a \quad m w-a \quad K a l u m b u \underline{b i}-1$-ingia

8-DEM 8-thing 8-all 8-PST-be-ASP 18-CON Kalumbu 8-PST-enter

umu mu-nyumba.

DEM.18 18-9.house

'All the stuff that was in Kalumbu's (house) was transferred into this house.

e. Lu-pi lu-le ba-li-mu-pika kuko Charles njo $\underline{\text { lu}}$-li-mu-vimbisha 11-slap 11-DEM 2-PST-1-hit by Charles it.is 11-PST-1-make swell di-cafu.

5-cheek

'The slap he was given by Charles is what made his cheek swollen.'

f. Mi-shi-ya-shikia-ka m-ambo y-a vile ku-ka-bila ata 1S-NEG-ASP-hear-ASP 6-matter 6-CON that way 17-12-tribe even

ka-moya $\underline{k}$-a umu mw-etu.

12-one 12-CON DEM.6 6-our

'I have never heard of such things in any of our tribes.'

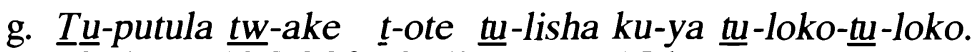

13-short 13-POSS 13-all 13-ASP 15-be 13-small-13-small

'All his pairs of shorts have become smaller.'

h. Tu-li-kombana bu-komvi bu-moya $\underline{b w}-a \quad n-g u v u$ sana. 1P-PST-fight 14-fight 14-one 14-CON 9-strength very' 'We fought a very hard fight.'

i. $\underline{K u}$-le $\underline{k u}$-lamukiana $\quad \underline{k w}$-a i-le saa mi-shi- $\underline{k} w$-icike. 15-DEM 15-greet each other 15-CON 9-DEM 9.time 1S-NEG-15-accept 'I don' $t$ believe in greeting people at that time.'

These examples clearly testify to the existence in CCS of the noun classes generally identified with the following prefixes, respectively: class 2 (ba-), class $5(\mathrm{di}-)$, class $7(\mathrm{ki}-)$, class $8(\mathrm{bi}-)$, class $11(\mathrm{lu}-)$, class $12(\mathrm{ka}-)$, class $13(\mathrm{tu}-)$, class 14 ( $b u-)$, and class 15 ( $k u-)$. To these can be added the three locative classes. These, too, have alliterative concord as indicated by the examples in (2) which 
represent classes $16(\mathrm{pa}-), 17(\mathrm{ku}-)$, and $18(\mathrm{mu}-)$, respectively. The fact that these locative prefixes are attached to full-fledged nouns (i.e., to nouns made up of a stem and the appropriate prefix) is not peculiar to CCS; the phenomenon is widespread in Bantu languages.

(2) a. A-li-sema a-li-shikia sa pa-ma-lata pa-li-kwa mu-ntu.

1-PST-say 1-PST-hear as if 16-6-roof 16-PST-be 1-man

'He said he had the impression that there was someone on the roof.'

b. $\underline{K u}$-n-sumishi $\underline{k}$-ote $\underline{\mathrm{ku}}$-li-kwa ma-lamu.

17-9-shirt 17-all 17-PST-be 6-blood

'There was blood all over the shirt.'

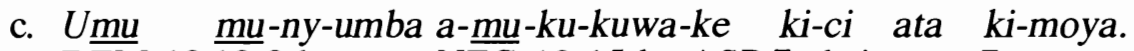

DEM-18 18-9-house NEG-18-15-be-ASP 7-chair even 7-one 'There was even not a single chair in this house.'

The noun classes thus far identified have in common the fact that the agreement marker is the same in form as the noun prefix. With the other classes, exemplified in (3) below, this is not the case. Nevertheless, there is a specific agreement pattern that identifies each class, thus complying with the view that a noun class is "made up of those words that have similar prefixes, which in turn form part of a set of concord elements operating a distinct pattern of agreement" [Guthrie 1956:545].

(3) a. Uyu $\underline{m u}-k u b w a \underline{a}-n a \quad \underline{m u}-n t u \underline{w}-a \quad k u-w e k e a$ ro.

1.DEM 1-elder 1-NEG.be 1-man 1-CON 15-put heart'

'This our elder brother is not someone to trust.'

b. Sasa a-n-ekala-ka paka ku-mu-kongo mu i-le $\underline{m u-m-p a n d o}$ now 1-PR-sit-ASP only 17-3-back 18 9-DEM 18-9-reclining chair $\underline{m u}$-lefu i-le $\underline{i}$-li-kuwa-ka y-a baba. 18-long 9-DEM 9-PST-be-ASP 9-CON father

'Now, he only sits behind the house in that long reclining chair that used to belong to dad.'

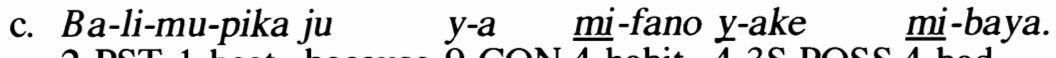
2-PST-1-beat because 9-CON 4-habit 4-3S.POSS 4-bad 'He was beaten up because of his bad habits.'

d. Má-co na-yo î-li-kwa $y$-a ku-vimba. 6-eye and-6 6-PST-be 6-CON 15-swell 'The eyes, too, were swollen.'

The situation is not straightforward with the traditional classes 9 and 10 , as can be seen from the examples in (4) and (5) below. Nouns like those in (4) and 
(5) are undifferentiated for singular (a) and plural (b), operating with the same concord set. Hence, there is no basis for justifying a class 9 different from class 10 in present day CCS. The two classes have obviously collapsed and their nouns can justifiably be lumped together into one class, which we can label as 9 .

(4) a. Shi-pende m-pango moya uku, $\underline{i}$-ngine kule. NEG-PR-like 9(sg)-plot.of.land 9.one here 9-other there 'I don't want one plot of land here, another one there.'

b. Mi-na-taka $\underline{m}$-pango $\underline{m}$-bidi $\underline{m u}$-nene sa $\underline{i}$ yi. 1S-PR-want 9(pl)-plot of.land 9-two 9-large like 9-DEM 'I want two plots of land this large.'

(5) a. M-pete $\quad y$-a pa-di-beka, ata kama i-ko moya tu, 9(sg)-stripe 9-CON16-5-shoulder even if 9-be 9.one only 'Even one stripe on the shoulder

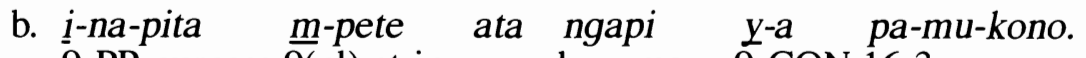
9-PR-surpass 9(pl)-stripe even how.many 9-CON 16-3-arm is superior to however many stripes on the arm.'

The table in (6) summarizes the information thus far provided with respect to noun class and concordial prefixes. The information in the chart is clearly at variance with previous scholars' views. For Polomé [1968], classes 12 and 13 do not exist in CCS, while classes 11 and 14 are said to have collapsed. Bokamba [1977] considers classes 12 through 15 to be non-existent. For his part, Rossé [1977] makes no mention of classes $3,4,11$, and 15 .

With respect to concord, it is interesting to realise that the nine classes which in Proto-Bantu operated with alliterative concord are also attested in CCS. These are the classes whose nouns have non-nasal $\mathrm{CV}$ prefixes and whose concord is, in fact, a copy of that CV. With the exception of class 1 , as can be seen in (7), all classes with $\mathrm{N}(\mathrm{V})$-prefixes follow the same agreement pattern for demonstratives $(i-)$, pronouns $(i$ - or $-y o)$, and verbs $(i-)$; class 4 differs from the others only in its agreement with adjectives. This sharing of agreement set is not peculiar to CCS. Ruund, a language of zone $\mathrm{K}$, uses the same concord pattern (with / yi-/ throughout) for both classes 4 and 8 .

Since these findings are based on a careful study of data produced by native speakers, it can be surmised that the main fault with previous work is inadequate or inappopriate data. Moreover, researchers seem to have failed to realise that the sirnplified system which they describe is no more than one aspect of an inflection/derivation-motivated system operating alongside the purely formal system presented above. This alternative system is discussed in a more detail in 3.2. 
(6) Noun class prefixes and associated concord sets

\begin{tabular}{|c|c|c|c|c|c|}
\hline \multirow[b]{2}{*}{$\mathrm{CL}$} & \multirow[b]{2}{*}{ Pfx } & \multicolumn{4}{|c|}{ Concordial Affixes } \\
\hline & & Demon. & Adjectives & Pronouns & Verbs \\
\hline 1 & mu- & $\mathrm{u}-$ & mu- & u- / -ye & a- \\
\hline 2 & ba- & ba- & ba- & ba- / -bo & ba- \\
\hline 3 & mu- & i- & mu- & i- / -yo & i- \\
\hline 4 & mi- & i- & mi- & i- / -yo & i- \\
\hline 5 & di- & di- & di- & di- / -dio & di- \\
\hline 6 & ma- & i- & mu- & i- / -yo & i- \\
\hline 7 & ki- & ki- & ki- & ki- / -kyo & ki- \\
\hline 8 & bi- & bi- & bi- & bi- / -kyo & bi- \\
\hline 9 & $n-$ & i- & mu- & i- / -yo & i- \\
\hline 11 & lu- & lu- & lu- & lu- / -lo & lu- \\
\hline 12 & ka- & ka- & ka- & ka- / -ko & ka- \\
\hline 13 & tu- & tu- & tu- & tu- / -to & tu- \\
\hline 14 & bu- & bu- & bu- & bu- / -bo & bu- \\
\hline 15 & ku- & ku- & ku- & ku- / -ko & ku- \\
\hline
\end{tabular}

(7) Prefixes of the N(V) type with associated concord sets

Concordial affixes

\begin{tabular}{ll|llll} 
CL & Pfx & Demon. & Adjectives & Pronouns & Verbs \\
\cline { 3 - 6 } 1 & mu- & u- & mu- & u- / -ye & a- \\
3 & mu- & i- & mu- & i- / -yo & i- \\
4 & mi- & i- & mi- & i- / -yo & i- \\
6 & ma- & i- & mu- & i- / -yo & i- \\
9 & n- & i- & mu- & i- / -yo & i-
\end{tabular}

3.2. The alternative pattern. There is evidence that CCS has another way of classifying nouns and determining concord. In this alternative system, nouns that are already marked with a prefix are allocated an additional prefix to mark the singular/plural distinction or a variety of derivationally obtained meanings. It will be seen from the appropriate examples that in such cases, agreement is triggered by the additional, leftmost prefix. Probably the most interesting characteristic of this system is the overriding role played by the prefixes / ba-/ and / ma-/ as pluralisers for any animate and inanimate nouns, respectively. In the following sets of examples, the underlined noun normally forms its plural as in the (a) examples. However, the form in the (b) examples is also grammatical in CCS. 
(8) a. Lumba a-li-bamba mi-longe mi-nene y-a mingi.

Lumba 1-PST-catch 4-herring 4-big 4-CON many

b. Lumba alibamba ba-mi-longe ba-nene $b$-a mingi.

$$
\text { 2-4-herring 2-big 2-CON }
$$

'Lumba caught many big herring.'

(9) a. Mbuya a-na-fundishaka bi-pofu.

Mbuya 1-PR-teach 8-blind

b. Mbuya anafundishaka $\frac{\text { ba-bi-pofu. }}{2-8 \text {-blind }}$

'Mbuya teaches the blind.'

(10) a. Ba-ntu a-ba-pende ma-tafwadi y-a ivi.

2-people NEG-2-like 6-bricks 6-CON like.this

b. Bantu abapende ma-ma-tafwadi ya $\frac{\text { 6-6-bricks }}{6-\mathrm{CON}}$ ivi.

'People don't like bricks of this sort.'

(11) a. $\frac{T \text { u-congola }}{13 \text {-sharpener } 13 \text {-ko ware where }}$

b. Ma-tu-congola iko wapi?

6-13-sharpener

'Where are the sharpeners?'

Evidence also exists which shows that CCS allows all singular inanimate nouns, on the one hand, to take the class 6 agreement marker, and all singular animate nouns, on the other, to take the class 1 agreement marker irrespective of their inherent noun class prefixes. Examples in (12) and (13) illustrate this for animate nouns. This alternation in agreement pattern - that is, between inherent class marker and the animate marker-is not applicable in east coast Swahili where human nouns with prefixes other than that of class 1 only permit the class 1 agreement pattern.

(12) a. Ki-le $\underline{k i}$-pofu $\underline{k i}$-na-fundaka kule. 7-that 7-blind person 7-PR-study there

b. $\underline{U}$-le $\underline{\text { ki-pofu }} \underline{\text { a-na-fundaka kule. }}$ 1-that 7-blind person 1-PR-study there

'That blind person studies there.' 
(13) a. Nani a-na-sabu ka-le ka-comona $\underline{k}$-a ma-shiku y-ote? who 1-PR-forget 12 -that 12 -pickpocket 12 -CON 6-days 6-all

b. Nani anasabu $\frac{\underline{u}-l e}{1-\text { that }} \frac{\text { ka-comona }}{12 \text {-pickpocket } \frac{W}{1}-\mathrm{CON}}$ mashiku yote? 'Who doesn't know that pickpocket of all days?'

What seems to be unique to CCS, and not found in other languages that have shifted to an animate/inanimate basis for determining agreement, is the selection of the $\mathrm{N}(\mathrm{V})$ class 6 agreement for all singular inanimate nouns, as (14) illustrates.

(14) a. Idi di this.5 5-bullet is 5-CON FM who 1-PST-bring-5 / 1-PST-5-bring

b. Iyi disashi ni $\underset{\text { 6.this }}{\text { 6-CON }} \begin{array}{r}\text { FM. Nani a-li-teta-yo / a-li-i-leta? } \\ \text { 1-PST-bring-6/ 1-PST-6-bring }\end{array}$ 'This is an FM bullet. Who brought it?'

It appears that CCS, in this alternative noun agreement system outlined in (15), has developed special concord patterns marking only singular/plural distinctions based on an animate/inanimate distinction. The noun prefixes and associated agreement patterns in this schema can, in compliance with restrictions imposed by certain syntactic environments, substitute for their homologues in (6) above.

(15) Simplified noun classification and related concord

\begin{tabular}{|c|c|c|c|c|c|c|}
\hline & \multirow[t]{2}{*}{ Number } & \multirow[t]{2}{*}{$N P f x$} & \multirow{2}{*}{\multicolumn{3}{|c|}{$\begin{array}{c}\text { Con cord } \\
\text { Adi }\end{array}$}} & \multirow[b]{2}{*}{ Verb } \\
\hline & & & & & & \\
\hline Animate & $\begin{array}{l}\text { Singular } \\
\text { Plural }\end{array}$ & $\begin{array}{l}\varnothing \\
\text { ba- }\end{array}$ & $\begin{array}{l}u- \\
b a-\end{array}$ & $\begin{array}{l}\text { u- } \\
b a-\end{array}$ & $\begin{array}{l}\text { u- / -ye } \\
b a-/-b o\end{array}$ & $\begin{array}{l}a- \\
b a-\end{array}$ \\
\hline Inanimate & Singular & $\varnothing$ & i- & $i-$ & i- / -yo & i- \\
\hline & Plural & ma- & $i-$ & $i-$ & i- / -уо & $i-$ \\
\hline
\end{tabular}

Details of the syntactic restrictions mentioned above are given in section 4 below. Before considering those restrictions, let us look at the derivational use of prefixes in CCS.

CCS exploits the resource of derivation via noun prefixes in basically the same way as all other Bantu languages. It selects particular prefixes, notably / ka-/, / ki-/, $/ / \mathrm{l}-\mathrm{-}, \mathrm{bu}-/ \mathrm{and}$ their plural counterparts (where applicable) to mark the notions of diminution, augmentation, deprecation, and status/quality, respectively. What is typical in this respect is the strong tendency for these prefixes to be added, not to the noun stems, but to the full noun-class prefix plus stem-as was the case with the pluralisers / $\mathrm{ba}-/$ and /ma-/. Taking the noun stems -todilo (3/4, flute) and -fwebe ( $7 / 8$, masquerade) for illustration, we find the forms given in (16)-(17). 
Singular Plural Gloss
(16) a. mutodilo
mitodilo
'flute(s)'
b. kamutodilo
tumitodilo
'small flute(s)'
c. kimutodilo
bimitodilo
'big flute(s)'
(17)
a. kifwebe
bifwebe
b. kakifwebe
tubifwebe
'masquerade actor(s)'
c. kikifwebe
bibifwebe
'small masquerade actor(s)'
d. lukifwebe
'big masquerade actor(s)'
'repulsive masquerade actor'
e. bukifwebe
'masquerade actor status'

Since derivational prefixes occupy the leftmost position in the noun structure, they take precedence over the strictly inflectional ones when it comes to triggering agreement. The same goes for locative prefixes as illustrated previously by the examples in (2).

That locative prefixes are added to nouns already bearing a class prefix is not unusual for a Bantu language. But that the other derivational prefixes and the pluralisers $/ \mathrm{ba}-/$ and $/ \mathrm{ma}-/$ also behave in this way suggests that the behaviour of prefixes in this alternative, simplified grammar may have been modelled on the locative prefixes. The situation seems to be one where, in addition to developing a generalised inanimate concord by analogy with animacy agreement, CCS is extending the syntactic behaviour of locative prefixes to other prefixes selected for marking number and derivational distinctions.

\section{Concordial and prefixal free variation}

It has been pointed out that the prefixes and concord sets of both the simplified and the conventional Bantu type of system share distribution throughout the CCS speech community. Close inspection of the linguistic contexts open to this variation reveals nonetheless that things are not as simple as they seem to be. Certainly contexts exist in which it does not matter which variant is used. But there also exist environments where the tendency is for variants of one system to supplant those of the other. And in still other environments, free variation is blocked altogether.

Concordial free variation is disallowed in at least two types of construction: those in which the noun commanding agreement has a derivational prefix in its morphology and those involving some re-ordering or disruption of the canonical SVO order of sentence constituents in CCS. The only concord type applicable in such contexts is that outlined in the conventional Bantu system given earlier in (6) above and exemplified in (18) and (19). This will, for convenience, be referred to as "strong concord"; concord in the simplified system will be referred to as "weak concord". 
(18) a. $\underline{T} \underline{u}$-bi-vidingo $\underline{t w}-a$ ndani $\underline{t u}$-na-pita bu-loko.

13-8-circle 13-CON inside 13-PR-surpass 14-smallness

b. *Tubividingo y-a ndani i-na-pita buloko.

13-8-circle 6-CON 6-PR-surpass

'The inner circles are too small.'

(19) a. Ka-lu-sambo ka-na-toka-mo.

12-11-wire 12-PR-get out-LOC

b. * Ka-lu-sambo i-na-toka-mo.

6-PR-get out-LOC

'The fuse has come off.'

Matters are further clarified when these facts are contrasted with the examples in (20) and (21), respectively, where the same nouns can trigger either concord freely because they are devoid of derivational prefixes.

(20) a. $\underline{B}$ i-vidingo by-a ndani bi-na-pita bu-loko.

8-circle 13-CON inside 13-PR-surpass 14-smallness

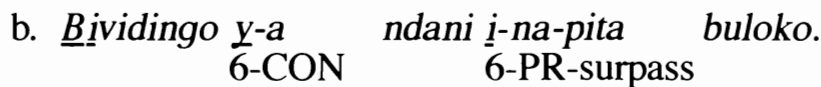

'The inner circles are too small.'

(21) a. Lú-sambo $\underline{\text { lu}}$-na-toka-mo.

11-wire 11-PR-get out-LOC

b. Lú -sambo $\underline{i}$-na-toka-mo.

6-PR-get out-LOC

'The fuse has come off.'

With (22) and (23), we have cases of obligatory use of strong concord when there is a marked word order.

(22) a. Ki-le mi-li-taka ki-na-onokana.

7-that 1S.PST-want 7-PR-reveal self

b. *Kile militaka i-na-onokana

6-PR-reveal self

'What I wanted has materialised.'

(23) a. Bi $\underline{i}$-fu u-ta-katulula- $\underline{b y o}$ kama bi-na-lekea.

8-tripe 2S-FUT-slice.up-8 if 8-PR-become soft

b. * Bifu utakatulula-yo kama i-na-lekea

-6 6-PR-become soft

'The tripe you will slice up when soft.' 
Thus, concordial free variation in CCS is only open to unmarked environments, marked ones being exclusively reserved for strong concord. In effect, by starting with an object constituent where the basic word order is normally subject initial, pseudo-cleft sentences and constructions with topicalised constituents as illustrated by the latter two examples are marked and, consequently, do not allow weak concord. The same applies to heads and and their dependents in relative clauses, cleft sentences, and sentences with dislocated constituents. For their part, nouns with derivational prefixes are considered marked by virtue of their semantic and morphological loads as compared to nouns with inflectional prefixes only.

The conclusion arising from these observations is that only strong concord is possible in marked environments; concordial free variation is only allowed in unmarked ones. Syntactic environments where only weak concord is applicable have not been identified. Those where it supplants strong concord are not much attested in the data either, despite informants' tendencies to accept them during consultations on acceptability and grammaticality. To have a clearer idea of the low frequency of weak concord in actual speech, note that this concord was only realised 26 times in a selected sample of conversations and narratives with 354 nouns capable of governing concord (which represents only $7 \%$ of cases in the selected range). Also interesting is the observation that the majority of cases forming this total of $7 \%$ are expounded within NPs, especially by possessive and connective markers. So, on the whole, we note that strong concord prevails both in marked and in unmarked environments while weak forms of agreement tend to be favoured on strictly grammatical (as opposed to lexical) formatives occurring NP internally, a point calling for further research and explanation.

An attempt to study the data from a sociolinguistic perspective shows that speakers alternate between the two concord types almost inadvertently. There thus does not seem to be any bssis for associating strong or weak concord with clearly specifiable sociolinguistic variables. The random character of concordial free variation in unmarked syntactic environments in spontaneously delivered speech is borne out by (24). In this example, MW (a minimally literate lady of 28 ) and KS (a male teacher of 35), carry on a conversation focussed on the theme -diyo (7/8, mourning) and give rise to a stretch of discourse where variants of the two concord types are clustered in probably the most ideal way. Markers of strong concord are underlined twice while those of weak concord have single underlining. The passage shows how each conversant freely goes from one concord type to the other.

(24) MW: Alisema uko muntu mubaya ju ya nini?

KS: Ju mishikukwende ku kidiyo kya kwabo.

MW: Beko na kidiyo kingine kya nani tena?

KS: Kidiyo kingine kya wapi! Shi paka ile kidiyo ya bab'abo. Milimwambia asema miye, tulisha kufwanya kidiyo kwa Paul. Je ne vois pas pourquoi il faut kufwanyulula ille kidiyo. Mitenda paka kama ni kidiyo kingine, kya muntu wingine anakufwa. 


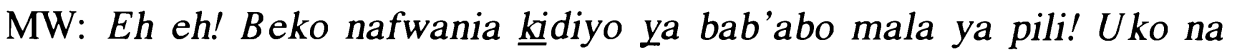
raison lwako.

KS: Oui, oui. Pour moi kidiyo $\underline{\underline{k i n}}$ esha kwisha.

[MW: Why did he say you are a bad person?

KS: Because I did not attend the mourning gathering in memory of their father.

MW: Who are they mourning again?

KS: Who else if not their father! I told him that as far as I'm concerned, the mourning gathering took place at Paul's. I don't see why it must be done again. I shall only go when someone else dies.

MW: So they are holding another mourning gathering in memory of their father! You are dead right.

KS: Yes. Yes. As far as I'm concerned, the mourning is over.]

An explanation of a stylistic nature comes with epistolary data. A perusal of the ten elicited letters revealed the exclusive use of strong concord in all contexts where agreement is required. Out of 480 such contexts identified in the 20 genuine letters, only three cases of weak concord were attested. As was the case with weak concord in spoken data, here too, the three intriguing situations involved the possessive clitics -ake 'his/hers' and -abo 'theirs', as (25)-(27) show.

(25) Mi-li-pata barua y-ako i-le u-li-tuma na mw-alimu y-ako. ${ }^{2}$ 1S-PST-get 9.letter 9-your 9-that 2S-PST-send with 1-teacher 6-your 'I received the letter that you sent with your teacher.'

(26) Paka mu-yomba y-enu njo eko nagonjwa. only 1-uncle your (pl) it.is is PR-be ill 'Only your uncle is ill.'

(27) Salimia bwana' ko. greet husband your Extend my greetings to your husband.'

These three cases were rephrased as in (28)-(30) during the consultations on acceptability and grammaticality.

(28) Milipata barua yako ile ulituma na mwalimu wako.

(29) Paka muyomba wenu njo eko nagonjwa.

(30) Salimia bwana wako.

Also noteworthy is the realisation of the possessive clitic in (27), which suggests that the writer, feeling inadequate with the realisation bwana yako 
which he probably resorts to in speech, prefers an alternative that masks weak concord in writing.

The reason for eschewing weak concord in favour of strong concord in writing seems simple: unlike spoken language which operates via the pragmatic mode of discourse [Givón 1979; Ochs 1979] and allows for little language monitoring before speech delivery, written language involves some syntactic tightening following the availability in this medium of more time for pre-planning and reformulation. The requirement of strong concord in the written data can thus be associated with the careful end of the careful-to-casual speech style continuum.

The same explanation can be extended to the previously identified marked syntactic environments involving dislocation, topicalisation, clefting, and relativisation as they emerge through syntactic elaboration of structures of the pragmatic mode [Givón 1979:222]. There is nothing inadequate with stating that free variation is blocked in favour of strong concord in constructions with displaced constituents or disrupted word order. But much is gained explanatorily by correlating strong concord, which occurs in marked environments, with careful style in which more attention is accorded the morphosyntax of constructions.

This stylistic explanation also works with respect to the choice of plural prefixes. Those of the simplified system were unattested in the written data. Even in speech, the plural prefixes of the original Bantu type supplant those of the simplified grammar. A ratio of 2 in 10 was observed in a sample of spoken discourse with 120 environments theoretically open to prefixal free variation. What is worth noting is that the pluralisers of the simplified system have proven to have a priviledge of occurence at hesitation points, which are typical of casual speech. This is illustrated in (31) and (32) where it is possible to replace the underlined words by bici 'chairs' and bitoyo 'salted fish', respectively.

(31) Jules ye eko nadidia ni fwashi.

Jules 1 PR-be PR-cry is space

Ana na mambo na nani...na mabici ya Nsamba.

NEG-be with 6-matter with what with 6-8-chair 6-CON Nsamba

'As for Jules, he is dying for space. He's got nothing to do with Nsamba's chairs.'

(32) Banauzishaka bitumbula, mikate na manani...mabitoyo na mafuta. 2-PR-sell-ASP 8-pancake 4-bread with 6-what 6-8-salted with 6-oil

They sell pancakes, bread, and what-d'you-call-it, salted fish and oil.

As in the case of concordial free variation, attempts at discovering sociolinguistic variables behind the selection of prefix variants were inconclusive.

On the whole, then, it seems that even though areas of overlap exist, the prefixes and concord sets of the conventional Bantu type of system are most appropriate in careful speech while their homologues from the simplified system are best fit for the casual end of the speech style continuum. As to the question of why analytic preference should be given to a continuum rather than to a discrete, 
diglossic analysis, one must note that there does not exist throughout the CCS speech community two distinct varieties of Swahili operating side-by-side, each with a definite social function.

With respect to so-called Standard Swahili, which advocates of a diaglossic analysis [Polomé 1968; Rossé 1977] would regard as the H(igh) variety, the majority of CCS speakers have no clear conception. It appears both from informants' pronouncements and the genuine letters in the data that what they call Standard Swahili is no more than a set of stereotypical items in the direction of which, to borrow Le Page and Tabouret-Keller's [1985:180] expression, a few gestures are made from time to time. Fabian [1984:181] remarks that despite all the effort for its promotion, "the refined, literary variety modelled on descriptions of east coast Swahili has always failed to develop into a vital linguistic medium."

\section{Conclusion}

The above discussion demonstrates that CCS has, in fact, a formal conventional set of noun class prefixes and related concord sets, the existence of which has been ignored in previous work. In addition to describing this system of purely formal concord classes and showing that the prefix shapes in this system correspond in general outline to those found in east coast Swahili, the paper has also shown that an alternative, simplified system also exists. In the latter, a limited number of original Bantu markers have been selected to express certain inflectional and derivational distinctions. The simpler system, involving agreement based on animacy of the noun, has developed inanimate as well as animate concord.

On the issue of prefixal and concordial free variation, one key point was made: forms of the original Bantu type of system are the only ones permitted in careful speech style while they share distribution with their homologues from the simplified system towards the casual end of the careful-to-casual speech continuum. Strong concord occurs exclusively in marked syntactic contexts including those where nouns embody a derivational prefix and those which involve movement rules such as topicalisation and clefting.

Given the pervasive character of the original Bantu type of noun class and concord variants, there is every reason to believe that the simplified noun classifi cation and agreement organisation form part of innovations the language is undergoing. The fact that new pluralisers are being introduced and that the prefixes and concord of the original Bantu type are excluding, as it were, their simplified counterparts from marked linguistic contexts seems to suggest that the language is developing a tendency to go away from a class system towards a system of singular/plural prefixes where the singular is unmarked and the plural marked.

Overall, it seems that, instead of putting back Bantu features into its reputedly pidginised grammar, as maintained by advocates of rebantuisation theory [Heine 1979; Polomé 1983], CCS is reverting to some sort of pidginisation by simplifying its noun class and agreement organisation. Note that such a course of development is not peculiar to CCS. It was followed by Kituba [Stucky 1978] and 
is operative in the urban Lingala of Kinshasa. Maybe the fact is that Bantu linguae francae are prone to this kind of change where a standard form is nonexistent or where attempts at institutionalising one have failed.

\section{REFERENCES}

Bokamba, E. G. 1977. "The impact of multilingualism on language structures: The case of central Africa." Anthropological Linguistics 5: 181-202.

Fabian, Johannes. 1984. "Mission and the colonisation of African languages: Development in the former Belgian Congo." Canadian Journal of African Studies 17/2: 4-11

Gilman, Charles. 1985. Pidgin Languages: Form Selection or Simplification. Indiana University Linguistic Club.

Givón, Talmy. 1979. On Understanding Grammar. New York: Academic Press.

Guthrie, Malcolm. 1956. "Observations on nominal classes in Bantu." Bulletin of SOAS 18,2: 545-55.

Heine, Bernd. 1979. "Some linguistic characteristics of African-based pidgins." In Ian F. Hancock (ed.), Readings in Creole Studies. Ghent: E Story-Scentia. Pp. 89-98.

Le Page, R. B. and A. Tabouret-Keller. 1985. Acts of Identity. Cambridge University Press.

Ochs, Elinor. 1979. "Planned and unplanned discourse.” In Talmy Givón (ed.), Syntax and Semantics Vol. 12 (Discourse and Syntax). New York: Academic Press. Pp. 51-80.

Ohly, R. 1988. "Sociolectal divergence in dialectometrics." South African Journal of African Languages 8, 1:16-22.

Polomé, Edgar. 1968. "Lubumbashi Swahili." Journal of African Languages 7,1: 14-25.

Polomé, Edgar. 1971. “Katanga (Lubumbashi) Swahili Creole.” In D. Hymes (ed.), Pidginisation and Creolisation of Languages. Cambridge University Press. Pp. 57-60. 
Polomé, Edgar. 1982. "Swahili pidgins." Paper presented to the Conference on Swahill Language and Society. London (SOAS): April 20-22.

Polomé, Edgar. 1983. "Creolisation and language change." In E. Woolford and W. Washabaugh (eds.), The Social Context of Creolisation. Ann Arbor, Michigan: Koroma Publishers.

Rossé, René. 1977. "Le Swahili populaire de Lubumbashi." Doctoral thesis: Université de Nice.

Stucky, E. 1978. "How a noun class system may be lost: Evidence from Kituba (Lingua Franca Kikongo)." Studies in the Linguistic Sciences 8,1: 216-32.

Institut Pédagogique National

B.P. 1826

Kinshasa

Democratic Republic of Congo
[Received October 1992; revision received May 1994; final revision received May 1999; accepted June 1999] 